\title{
A INSERÇÃO DA AGROECOLOGIA EM UM NOVO SISTEMA ALIMENTAR PÓS- COVID-19
}

João Henrique Constantino Sales Silva ${ }^{1}$

Alex da Silva Barbosa ${ }^{2}$

Resumo: A lógica do atual sistema alimentar tem sido incapaz de gerar saúde respeitando os limites do planeta. Assim sendo, o presente trabalho propõe uma reflexão acerca da inserção da agroecologia em um novo sistema alimentar pautado na construção de sociedades sustentáveis em tempos de crise ambiental e de saúde global. A pandemia provocada pelo vírus SARSCoV-2 está profundamente associada com a ruptura ecológica produzida pelo sistema convencional de produção de alimentos. A atual crise mundial ressalta a necessidade de um sistema agroalimentar mais sustentável, e a agroecologia, que além de atender as demandas das famílias rurais, garantindo benefícios sociais, econômicos e ambientais, também se apresenta como solução viável para atender as demandas urbanas.

Palavras-chave: Alimentação Saudável; Pandemia; Sistema Agroalimentar.

Abstract: The current food system framework is unable to generate health while respecting the limits of the planet. As such, the present study reflects on including agroecology in a new food system based constructing sustainable societies in times of global environmental and health crises. The SARS-CoV-2 pandemic is closely linked to the ecological disruption caused by the conventional food production system. The current global crisis highlights the need for a more sustainable agri-food system, and agroecology, which in addition to satisfying the needs of rural families and ensuring social, economic and environmental benefits, is also a viable solution to meet urban demands.

Keywords: Healthy Eating; Pandemic; Agri-food System.

\footnotetext{
1 Universidade Federal da Paraíba. E-mail: joaohenriqueconst@gmail.com, Lattes: http://lattes.cnpq.br/2532102683389507

2 Universidade Federal da Paraíba. E-mail: aldasibarbosa@gmail.com, Lattes: http://lattes.cnpq.br/0957218486770990
} 


\section{Introdução}

A maior parte dos nossos problemas globais, a exemplo da escassez de água e energia, poluição ambiental, mudanças climáticas, desigualdades socioeconômicas, insegurança alimentar, dentre outros, não podem ser vistos de forma dissociada, uma vez que um desiquilíbrio no sistema causa uma reação em cadeia, afetando as demais esferas desse sistema. Nesse sentido, a atual crise mundial provocada pelo vírus SARS-CoV-2, causador da enfermidade Coronavirus disease 2019 (COVID-19), faz-nos compreender o quão frágil e vulnerável é o nosso planeta, numa perspectiva sócioecológica; e que a agroecologia pode ajudar a explorar o elo existente entre agricultura e saúde (ALTIERI; NICHOLLS, 2020).

A declaração de pandemia da COVID-19 fez com que muitas pessoas ao redor do mundo mudassem suas rotinas de forma drástica. Mas, poucos são os que questionam as causas reais que levaram ao surgimento do vírus e ao fato de que, enquanto governos trabalham para contê-lo, outros vírus e pandemias continuam surgindo (RIBEIRO, 2020a). Ribeiro (2020b) menciona três possíveis causas, concomitantes e complementares, que produziram todos os vírus infecciosos que se propagaram mundialmente nas últimas décadas, sendo elas: 1) a criação de animais em confinamento; 2) o desmatamento da vegetação nativa, principalmente com finalidade de criação de pastos e monocultivos; e 3) o crescimento descontrolado da urbanização e das indústrias.

A pandemia do coronavírus mostrou que o homem e sua maneira inconsciente de consumir são um dos maiores culpados pelo que estamos vivenciando hoje (GLETTE, 2020). As restrições causadas pela pandemia da COVID-19 - devido ao necessário cumprimento do isolamento social, na expectativa de postergar a velocidade de contaminação do vírus - passaram a impor dificuldades para promover o abastecimento alimentar no Brasil. Multidimensional, a alimentação sempre refletiu as prioridades políticas e de desenvolvimento presentes na sociedade, e não seria diferente nesse contexto com o coronavírus (PORTO; GRISA, 2020).

$\mathrm{O}$ isolamento preventivo nos levou a repensar a nós mesmos, consumir estritamente o necessário, valorizar o trabalho dos camponeses e esperar que o mercado de frutas e verduras esteja disponível nas quitandas mais próxima ou venha à nossa porta. $O$ trabalho digno do feirante camponês, que há muito foi subordinado e marginalizado pelo agronegócio, está sendo reavaliado gradativamente neste período de distanciamento social, uma vez que as pessoas estão dando preferência a procurar suprimentos nas quitandas, pequenos mercados ou armazéns mais próximos, em vez de ir a centros comerciais lotados (LEAL, 2020).

Se uma ida ao mercado precisa de uma série de precauções e medidas de segurança, as compras online nunca se mostraram tão essenciais. No entanto, é preciso mais do que nunca saber de quem estamos comprando e 
valorizar pequenos produtores locais comprometidos com o meio ambiente (GLETTE, 2020). Nesse sentido, a agroecologia, mais do que uma alternativa, é uma necessidade para enfrentar a atual crise civilizacional, uma vez que ela é capaz de entrelaçar conhecimentos das ciências naturais e ciências sociais, rompendo assim a dicotomia cultura-natureza, visto que a agroecologia concebe o mundo a partir de uma perspectiva sócioecológica, onde tanto as desigualdades sociais como as ambientais fazem parte do todo (VALDERRAMA, 2020).

Ante ao exposto, a presente pesquisa bibliográfica propõe uma reflexão acerca da inserção da agroecologia em um novo sistema alimentar pautado na construção de sociedades sustentáveis em tempos de crise ambiental e de saúde global.

\section{O sistema convencional de produção de alimentos e a COVID-19}

Inúmeros estudos têm apontado para a insustentabilidade do atual sistema agroalimentar com produção em larga escala (ALENTEJANO, 2020). De acordo com alguns especialistas, enormes quantidades de animais de criação confinados, vacinados e imunodeprimidos fazem com que os vírus tenham mutações de forma mais rápida. Esses animais consomem antibióticos e antivirais continuamente, propiciando rusticidade e adaptação aos novos vírus. Além disso, os vírus podem passar de uma espécie à outra e embora possam originar-se em espécies silvestres, como aves e morcegos, é a destruição dos habitats naturais que fazem esses animais migrarem de suas áreas de ocorrência natural, onde as cepas dos vírus estavam controladas dentro de sua própria população (RIBEIRO, 2020a; RIBEIRO, 2020b). Ou seja, o avanço do desmatamento, por sua vez, leva animais silvestres que antes se encontravam nas florestas a se deslocar para outras áreas, inclusive urbanas, transformando-se também em vetores da disseminação de doenças.

Causas estruturais, assim como outros vírus (gripe aviária H5N1, gripe suína $\mathrm{H} 1 \mathrm{~N} 1$ e a doença da vaca louca), estão relacionadas a um sistema agroalimentar que se sustenta na ideia antropocêntrica de que certos animais (porcos, vacas, galinhas) são meros objetos para a exploração (VALDERRAMA, 2020). De acordo com este autor, o problema vai muito além do que suscita uma visão sanitarista, centrada na saúde pública, mas, sim, está em questionar um sistema de vida atual, que declarou guerra à mãe natureza, ao acreditar estar acima de seus limites. O modelo de produção de alimentos proposto pelo agronegócio, espalha vírus selvagens mortais para organismos adoecidos por alimentos cheios de açúcares, gorduras e agrotóxicos.

Esse sistema convencional de produção tem uma grande contribuição nas morbidades crônicas, a exemplo da diabetes e hipertensão arterial, que colocam muitas pessoas no grupo de risco, aumentando as chances de complicação pela COVID-19 (OLIVEIRA, 2020a). Além disso, o agronegócio tem como um dos principais pilares o uso de agrotóxicos e, atualmente, vários 
estudos relatam os malefícios destes à saúde humana e ambiental, como os trabalhos descritos por Carneiro et al. (2019), Mello et al. (2019), Pereira et al. (2019) e Haddad et al. (2019). Contudo, a pandemia de COVID-19 não foi motivo suficiente para que o atual governo brasileiro contivesse a liberação de novos agrotóxicos no país, visto que em março do decorrente ano foi dado aval para mais 53 agrotóxicos (leia atos $17^{3}$ e $22^{4}$ no Diário Oficial da União). Somando-se os 101 liberados apenas no primeiro trimestre de 2020 aos 503 liberados em 2019, tem-se o total de 604 novas liberações em 15 meses (OLIVEIRA, 2020a).

De acordo com Loureiro e Zarref (2020):

Por um lado, o envenenamento massivo da natureza estimula a seleção natural no sentido de surgirem variedades de vegetais, vírus, bactérias cada vez mais resistente. Por outro lado, vegetais, animais e seres humanos que estão subordinados à lógica alimentar das grandes transnacionais vão se tornando cada vez mais vulneráveis, com menos imunidade e resistência a essas doenças. O francês Francis Chaboussou, ao desenvolver a teoria da trofobiose para as plantas, afirmou que "solo doente, planta doente". Podemos reproduzir isso para todo 0 metabolismo socioecológico: alimento doente (ultraprocessado, pouco diverso, envenenado), ambiente doente (escassez hídrica, ausência de biodiversidade, poluições diversas), seres humanos doentes.

Pinheiro (2020) aponta o momento atual como oportuno para reconhecermos o impacto das escolhas alimentares sobre a saúde humana, ambiental e planetária, como: a iminente escassez dos recursos naturais, o desmatamento das florestas, a poluição do ar e dos solos, o aumento de doenças crônicas provocadas pelo uso e consumo excessivo de agrotóxicos, alimentos transgênicos e ultraprocessados, o extermínio das comunidades tradicionais e suas práticas ancestrais de respeito e preservação da natureza, o acúmulo de lixo reciclável e não reciclável sem tratamento e reaproveitamento correto, dentre outras questões ético-políticas que violam os direitos humanos, destroem a biodiversidade e ameaçam a sobrevivência do planeta.

As grandes metrópoles brasileiras são marcadas por profundas desigualdades, com trânsito caótico, falta de saneamento, ilhas de calor e

${ }^{3}$ BRASIL. Ato ํo 17, de 19 de março de 2019. Diário Oficial da União. República Federativa do Brasil. Disponível em: <http://www.in.gov.br/materia/lasset publisher/Kujrw0TZC2Mb/content/id/67956251 > Acesso: 26 abr. 2020.

${ }^{4}$ BRASIL. Ato ํㅡ 22, de 25 de março de 2019. Diário Oficial da União. República Federativa do Brasil. Disponível em: <http://www.in.gov.br/en/web/dou/-/ato-n-22-de-25-de-marco-de-2020249993273> Acesso: 26 abr. 2020. 
poluição, ambientes mais do que favoráveis à disseminação de epidemias e pandemias ligadas aos mais diferentes agentes infectocontagiosos. A desconcentração espacial da população brasileira através de uma ampla reforma agrária agroecológica permitiria ao mesmo tempo combater essas mazelas. Uma vez que há no Brasil 247,7 milhões de ha sob o controle do latifúndio, dos quais 175,9 milhões de ha são de terras improdutivas. Por outro lado, a área plantada com alimentos básicos (arroz, feijão e mandioca) diminuiu 5 milhões de ha nos últimos 30 anos. Portanto, reverter esse cenário é urgente e só uma reforma agrária agroecológica pode fazê-lo. Antes que se ampliem ainda mais a fome, a miséria e as doenças geradas por esse modelo agroalimentar dominado pelas grandes corporações do agronegócio (ALENTEJANO, 2020).

\section{A agroecologia perante as atuais crises socioambientais}

Em meio ao contexto de pandemia que se instaurou no mundo e no Brasil, muitas aldeias indígenas, quilombos, ribeirinhos e outras comunidades tradicionais que têm o turismo e o artesanato como uma fonte de renda, tiveram que limitar o acesso de pessoas vindas de fora de seus territórios. Assim sendo, muitas redes de solidariedade têm reforçado ações nas áreas de soberania e segurança alimentar, direito à terra e economia solidária para evitar que a fome e a falta de recursos essenciais cheguem às pessoas que estão em maior situação de vulnerabilidade (OTSS, 2020).

A crise causada pela pandemia do novo coronavírus veio alertar os países dependentes de importações de alimentos sobre o risco que essa dependência pode trazer à segurança alimentar nacional, fazendo-se necessário rever 0 abastecimento interno das importantes olerícolas (NASCIMENTO, 2020). De acordo com este autor, essa crise está sendo uma grande oportunidade para o governo, empresas, produtores e para a sociedade geral repensarem a sua atuação e a sua forma de organização em busca de caminhos alternativos.

Leal (2020, p.1) afirma que:

É hora de acreditar no campesinato, apoiá-lo, em vez de aplausos invisíveis por meio das redes sociais, com políticas públicas que thes proporcionem benefícios para melhorar sua qualidade de vida, para que mantenham a disponibilidade de alimentos e para que nosso país possa oferecer sua própria comida. 
soberania alimentar e utilizar a agroecologia para produzir alimentos sadios, se mostrou não apenas como uma política pontuada pelo MST ou de algum governo, mas, sim, uma necessidade real de sobrevivência das sociedades atuais. Além disso, no contexto de isolamento social das cidades, com o fechamento de fronteiras e as restrições ao comércio, é a Agroecologia e a produção camponesa que estão mantendo o abastecimento alimentar das cidades, fornecendo alimentos saudáveis e fortalecendo o comércio justo e solidário (LOUREIRO; ZARREF, 2020).

No momento da pandemia do coronavírus, inúmeros problemas têm dificultado o acesso aos alimentos. No entanto, a sociedade vem gerando outras estratégias de acesso à alimentação saudável, como os grupos de consumo. Estes grupos reúnem famílias, amigos ou indivíduos que, em parceria com assentados da reforma agrária, povos originários e comunidades tradicionais, planejam e financiam sistemas de produção de alimentos agroecológicos locais, de forma colaborativa, coletiva e solidária. Fortalecer estas aproximações em tempos de quarentena pode ser uma alternativa saudável para a sociedade e o meio ambiente (PINHEIRO, 2020).

No Estado do Rio de Janeiro, por exemplo, vários produtores agroecológicos se organizaram e expandiram sua clientela durante o avanço da pandemia. Diante da determinação de medidas de isolamento social, os pedidos por cestas de frutas, legumes, verduras e outros itens derivados da tradicional feira ecológica, quadruplicaram através de aplicativos e redes sociais, exigindo rapidez dos agricultores na revisão de suas estratégias de atuação para atender às demandas sem sobrecarregar os processos de produção (OLIVEIRA, 2020b). Acredita-se ainda, que esta tendência de consumo se firme, após a superação do isolamento preventivo, em reconhecimento à contribuição dessas práticas produtivas para a proteção ambiental e a saúde de produtores e consumidores.

Nessa perspectiva, o Instituto Brasileiro de Defesa do Consumidor criou a plataforma "Comida de Verdade", com o apoio de diversas organizações, para divulgar iniciativas que comercializam alimentos saudáveis durante a pandemia do COVID-19. A ferramenta tem o objetivo de apoiar a economia local e aproximar quem produz de quem consome. Nela, o usuário pode encontrar iniciativas da agricultura familiar, de pequenos produtores e dos sistemas de produção orgânica e agroecológica em todas as regiões do Brasil. Essa plataforma é um importante meio de informar às pessoas que, além dos mercados, existem canais alternativos para o abastecimento, seja em pontos de venda físicos ou na modalidade de entrega a domicílio (IDEC, 2020). Outra característica da plataforma é que os produtores, ou quem quiser contribuir, podem fazer novos cadastros.

Para escoar a produção de assentamentos da zona rural de Teresina $\mathrm{PI}$, produtores rurais e entidades ligadas à agricultura familiar realizaram um projeto piloto de venda de produtos como hortaliças, legumes e frutas via Drive Thru. Sem descer do carro, consumidores recolhem as cestas de produtos 
encomendados previamente pelo Whats $A p p$. Estas cestas variam de $R \$ 10$ a $R \$ 130$ reais, dependendo da quantidade de produtos que vão desde legumes a produtos manuseados como farinha e goma e a entrega é feita pelos próprios produtores, evitando o máximo de contato com os consumidores (MACÉDO, 2020). No Estado do Espírito Santo, alguns agricultores também comercializaram seus produtos nesta modalidade, como reportado por Nascimento e Esteves (2020). Essas iniciativas tiveram uma repercussão positiva, uma vez que são alternativas diante da suspensão das feiras livres e das aulas nas escolas, onde muitos agricultores comercializam produtos via Programa de Aquisição de Alimentos (PAA).

Outra iniciativa que ganhou notoriedade foi a criação do Portal dos Produtos da Agricultura Familiar pela Secretaria do Desenvolvimento Agrário do Governo do Ceará. O portal consiste numa ferramenta capaz de fortalecer a agricultura familiar, diminuir a vulnerabilidade e criar a perspectiva da renda, através da segurança alimentar. Pelo espaço de pesquisa da nova plataforma, compradores podem procurar pelo produto, região ou cidade de preferência e até mesmo a cooperativa responsável pelo gênero. Assim, ofertar alimentos como frutas, hortaliças e verduras de maneira dinâmica pode ajudar ainda na movimentação da economia (CELEDÔNIO; GURJÃO, 2020).

De acordo com Porto e Grisa (2020) o desafio nesse momento será o de assegurar diferentes mecanismos que contribuam para garantir o Direito Humano à Alimentação Adequada e Saudável (DHAAS), de um lado acelerando os repasses de transferência de renda e, de outro, potencializando diferentes estratégias de abastecimento alimentar. Ainda de acordo com esses autores, essas estratégias devem ser estabelecidas tanto por meio da ação do Estado quanto por iniciativas que promovam a construção social dos mercados, fortalecendo as relações diretas entre produtores e consumidores. Importante que essas estratégias considerem o papel multidimensional da alimentação e suas repercussões no desenvolvimento. Além de lidar com o contexto emergencial, essas medidas podem deixar um legado para novas ações estruturantes, contribuindo para colocar a alimentação no centro dos processos de desenvolvimento e das prioridades políticas, onde deve estar.

\section{Agroecologia, segurança alimentar e nutricional: um diálogo necessário}

De acordo com Moreira (2020), o momento histórico e conjuntural que vivemos é privilegiado para analisar mecanismos e tendências sociais em funcionamento há muitos anos, a exemplo das práticas agroecológicas e sustentáveis. Segundo este autor, manter um estilo de vida saudável e sustentável remete-nos a uma alimentação equilibrada e heterogênea, uma vez que os alimentos recomendados pelos imunologistas são, em maior ou menor medida, encontrados em abundância na natureza, e, sobretudo nos quintais, hortas familiares ou comunitárias, assentamentos da reforma agrária e feiras de produtores familiares e agroecológicos, o que ressalta os aspectos 
eminentemente sociais e ambientais da saúde e da medicina.

Nessa mesma linha de raciocínio, Melo et al. (2017) evidenciam o elo existente entre a agroecologia e nutrição e como esses dois pilares coexistem e caminham juntos na promoção da saúde ambiental e humana, nos seus mais complexos contextos. Para esses autores, não há como dissociar essas duas temáticas, visto que elas estão intimamente relacionadas à soberania e segurança alimentar e nutricional, à medicina popular e dietoterapia; e à promoção da saúde através de uma dieta heterogênea.

Loureiro e Zarref (2020) afirmam que:

Se compararmos a China com os EUA nessa pandemia atual, já podemos tirar algumas lições. Uma é que dentre os tratamentos utilizados na vitoriosa ação chinesa contra a doença, estão um conjunto de mais de uma dezena de plantas da medicina tradicional do país. Outra é o perfil epidemiológico da doença: enquanto na China o grupo de risco era quase exclusivamente idosos, nos EUA pessoas de 20 a 50 anos já representam $40 \%$ dos internados. Isso se deve à diferença de alimentação e práticas de saúde entre os dois países.

Segundo Altieri e Nicholls (2020), a agroecologia tem o potencial de produzir localmente grande parte dos alimentos necessários para as comunidades rurais e urbanas, particularmente em um mundo ameaçado pelas mudanças climáticas e outros distúrbios, como as pandemias de doenças. Ainda de acordo com esses autores, a ingestão de alimentos nutritivos à base de vegetais produzidos em propriedades agroecológicas locais pode ajudar a fortalecer nosso sistema imunológico, possivelmente melhorando nossa capacidade de resistir a várias ameaças, incluindo os vírus contagiosos como o SARS-CoV-2.

Nesse sentido, romper com o sistema alimentar hegemônico que potencializa a produção e comercialização dos produtos ultraprocessados, baseados em açúcares, gorduras, sódio, aditivos químicos e cada vez mais restritos a poucas culturas (como soja e milho), significa dar passos para reverter o quadro de agravo da saúde da população, refém das doenças crônicas como diabetes, hipertensão, obesidade, cânceres (LOUREIRO; ZARREF, 2020). Segundo esses autores, é na soberania alimentar proposta pela agroecologia que estão as chances de garantir às comunidades o acesso aos recursos naturais dos seus territórios, como água, terra, sementes, insumos e a biodiversidade. 


\section{Conclusões}

A pandemia provocada pelo vírus SARS-CoV-2 está profundamente associada com a ruptura ecológica produzida pelo sistema convencional de produção de alimentos. Embora se acredite numa origem zoonótica para a COVID-19, o problema de fundo passa pela destruição dos habitats naturais dos animais silvestres pela agricultura industrial aliada ao uso abusivo de antibióticos em animais confinados, o que gera as condições adequadas para as aceleradas mutações virais.

A atual crise mundial ressalta a necessidade de um sistema agroalimentar mais sustentável e diante da segurança e da soberania alimentar que a Agroecologia propõe, acredita-se que esta tendência de consumo se firme, após a superação do isolamento preventivo, em reconhecimento à contribuição dessas práticas produtivas para a proteção ambiental e a saúde de produtores e consumidores.

Considerando o crescimento da demanda de deliveries da agricultura familiar, tornam-se oportunas também ações e políticas que apoiem a estruturação desse novo mercado. Espera-se ainda, que a crise causada pela COVID-19 ajude a iluminar os caminhos das lutas futuras da humanidade em defesa de um novo mundo, solidário, justo e ecológico, pautado em maneiras mais suaves de interagir com a natureza.

\section{Referências}

ALENTEJANO, P. Crise do coronavírus alerta para necessidade de repensar produção alimentar. Centro de Documentação Eloy Ferreira da Silva (CEDEFES), 09 abr. 2020. Disponível em: $<$ https://www.cedefes.org.br/crise-do-coronavirus-alerta-para-necessidade-derepensar-producao-alimentar/> Acesso em: 01 mai. 2020.

ALTIERI, M.A.; NICHOLLS, C.I. La Agroecología en tiempos del covid-19., Centro Latinoamericano de Investigaciones Agroecológicas (CELIA), University of California, Berkeley, p.1-7, 2020. Disponível em: $<$ http://celia.agroeco.org/wp-content/uploads/2020/04/ultima-CELIAAgroecologia-COVID19-19Mar20.pdf> Acesso: 25 abr. 2020.

CARNEIRO, C.R.; ALMEIDA, J.C.; CASTRO, A.P. Agrotóxicos e as repercussões na saúde dos trabalhadores rurais. Revista Brasileira de Gestão Ambiental, v. 13, n. 1, p. 12-35, 2019.

CELEDÔNIO, E.M.; GURJÃO, A. SDA lança portal para facilitar comercialização de produtos da agricultura familiar. Secretaria do Desenvolvimento Agrário do Governo do Ceará, 28 abr. 2020. Disponível em: $<$ https://www.ceara.gov.br/2020/04/28/sda-lanca-portal-para-facilitar-

comercializacao-de-produtos-da-agricultura-familiar/> Acesso em: 30 abr. 2020. 
GLETTE, G. Lista de contatos de agricultores orgânicos e agroecológicos para compras conscientes. Hypeness. 2020. Disponível em: $<$ https://www.hypeness.com.br/2020/04/lista-de-contatos-de-agricultoresorganicos-e-agroecologicos-para-compras-conscientes/> Acesso em: 30 abr. 2020.

HADDAD, C.; RIBAS, D.S.; PEREIRA, G.A.; SILVA, R.J.M. Agrotóxicos no Brasil. Jornal Eletrônico Faculdade Vianna Júnior, v. 11, n. 1, p. 19-19, 2019.

IDEC. Idec cria plataforma para divulgar iniciativas que comercializam alimentos saudáveis durante a pandemia do Covid-19. Instituto Brasileiro de Defesa do Consumidor, 14 abr. 2020. Disponível em: $<$ https://idec.org.br/release/idec-cria-plataforma-para-divulgar-iniciativas-quecomercializam-alimentos-saudaveis-durante> Acesso em: 30 abr. 2020.

MACÊDO, F.V. Com proibição de feiras livres, drive thru vende produtos agroecológicos. Cidade Verde. 07 abr. 2020. Disponível em: $<$ https://cidadeverde.com/coronavirus/105547/com-proibicao-de-feiras-livresdrive-thru-vende-produtos-agroecologicos > Acesso em: 30 abr. 2020.

MELLO, F.A.; FAGIANI, M.A.B.; ROSSI, R.C.; NAI, G.A. Agrotóxicos: impactos ao meio ambiente e à saúde humana. Colloquium Vitae, v.11, n.2, p.37-44, 2019.

MELO, L.F.; SILVA, L.P.C. ; ARAÚJO, A.E. Agroecologia e nutrição: um diálogo possível. Anais... In: Congresso Internacional de Ciências Agrárias COINTER, 2017, Natal. Desenvolvimento do campo: a ciência e tecnologia a serviço da sustentabilidade, p. 1-9, 2017.

MOREIRA, J.S. Como passar pela pandemia com práticas agroecológicas e sustentáveis. H2FOZ. 16 mar. 2020. Diponível em: $<$ https://www.h2foz.com.br/noticia/como-passar-pela-pandemia-com-praticasagroecologicas-e-

sustentaveis?fbclid=IwAR3sT1iamhGADWgVt9J94rZZHADmR177Dxka68UO1 gq95DhtNQ4LiHV4U04>Acesso: 25 abr. 2020.

NASCIMENTO, H.; ESTEVES, J. Agricultores buscam meios de comercializar seus produtos durante a pandemia de Covid-19. Instituto Capixaba de Pesquisa, Assistência Técnica e Extensão Rural (Incaper). Governo do Estado do Espírito Santo. 30 mar. 2020. Disponível em: $<$ https://incaper.es.gov.br/Not\%C3\%ADcia/agricultores-buscam-meios-decomercializar-seus-produtos-durante-a-pandemia-de-covid-19> Acesso: 01 mai. 2020. 
NASCIMENTO, W.M. Crise do coronavírus afeta exportações e importações brasileiras de hortaliças. Empresa Brasileira de Pesquisa Agropecuária. Ministério da Agricultura, Pecuária e Abastecimento. 29 abr. 2020. Disponível em: <https://www.embrapa.br/busca-de-noticias//noticia/51886734/artigo-crise-do-coronavirus-afeta-exportacoes-e-importacoesbrasileiras-de-hortalicas> Acesso em: 29 abr. 2020.

LEAL, A.D. De la invisibilidad histórica, al elogio y el aplauso para el campesino. Corporación Universitaria Minuto de Dios-UNIMINUTO, Cundinamarca, Colombia, p.1-3, 2020. Disponível em: $<$ https://repository.uniminuto.edu/jspui/bitstream/10656/10098/1/Documento In visibilidad\%20del\%20campesinado.pdf> Acesso em: 29 abr. 2020.

LOUREIRO, B.; ZARREF, L. Produzir alimentos saudáveis e plantar árvores: a Reforma Agrária Popular no combate ao Coronavírus. Movimento dos Trabalhadores Rurais Sem Terra. 29 mar. 2020. Disponível em: $<$ https://mst.org.br/2020/03/29/produzir-alimentos-saudaveis-e-plantar-arvoresa-reforma-agraria-popular-no-combate-ao-coronavirus/> Acesso em: 30 abr. 2020.

OLIVEIRA, C. $O$ que o agronegócio e a produção de alimentos têm a ver com a covid-19? Rede Brasil Atual. 06 mar. 2020a. Disponível em: $<$ https://www.redebrasilatual.com.br/ambiente/2020/04/o-que-o-agronegocio-ea-producao-de-alimentos-tem-a-ver-com-a-covid-19/> Acesso: 26 abr. 2020.

OLIVEIRA, E. Covid-19: produtores orgânicos se organizam e expandem clientela no Rio. ((o))eco. 28 abr. 2020b. Disponível em: $<$ https://www.oeco.org.br/reportagens/covid-19-produtores-organicos-seorganizam-e-expandem-clientela-no-rio/> Acesso em: 30 abr. 2020.

OTSS. Agroecologia e solidariedade entre comunidades tradicionais no combate à COVID-19. Observatório de Territórios Sustentáveis e Saudáveis da Bocaina. 03 abr. 2020. Disponível em: $<$ https://www.otss.org.br/post/agroecologia-e-solidariedade-entre-comunidadestradicionais-no-combate-a-covid> Acesso: 29 abr. 2020.

PEREIRA, R.A.; COSTA, C.M.L.; LIMA, E M. O impacto dos agrotóxicos sobre a saúde humana e o meio ambiente. Revista Extensão, v. 3, n. 1, p. 29-37, 2019.

PINHEIRO, A.R.O. Agroecologia, Alimentação Saudável e Redes de Abastecimento. Portal de Notícias da Universidade de Brasília. 20 abr. 2020. Disponível em: <http://noticias.unb.br/artigos-main/4077-agroecologiaalimentacao-saudavel-e-redes-de-abastecimento > Acesso em: 01 mai. 2020.

PORTO, S.I.; GRISA, C. Abastecimento alimentar e prioridades políticas na pandemia da covid-19. Teoria e Dabete. 14 abr. 2020. Disponível em: $<$ https://teoriaedebate.org.br/2020/04/14/abastecimento-alimentar-e-

prioridades-politicas-na-pandemia-da-covid-19/> Acesso em: 01 mai. 2020. 
RIBEIRO, S. Coronavírus, agronegócio e estado de exceção. Brasil de Fato. 2020a. Disponível em: <https://www.brasildefato.com.br/2020/04/01/artigo-oslatifundiarios-da-pandemia-por-silvia-ribeiro> Acesso: 25 abr. 2020.

RIBEIRO, S. Os latifundiários da pandemia. Brasil de Fato. 01 abr. 2020b. Disponível em: <https://www.brasildefato.com.br/2020/04/01/artigo-oslatifundiarios-da-pandemia-por-silvia-ribeiro> Acesso: 25 abr 2020.

STEDILE, J. P. A agroecologia é o caminho pra sair da crise?. Movimento dos Trabalhadores Rurais Sem Terra. 26 mar. 2020. Disponível em: <https://mst.org.br/2020/03/26/a-agroecologia-e-o-caminho-pra-sair-da-crise/> Acesso em: 29 abr. 2020.

VALDERRAMA, A. K. Agroecología frente a las pandemias modernas. Observatorio Plurinacional de Aguas. 18 mar. 2020. Disponível em: < https://oplas.org/sitio/2020/03/18/agroecologia-frente-a-pandemias-modernas/> Acesso em: 25 abr. 2020. 